\title{
RANKING SCHOLARLY MARKETING JOURNALS BY MAJOR SUBAREA
}

\author{
Matt Elbeck, Troy University - Dothan, USA \\ Brian A. Vander Schee, Aurora University, USA
}

\begin{abstract}
This study seeks to rank scholarly marketing journals in five major subareas using website, opinion and citation data. The five major marketing subareas are identified as the most popular US marketing doctoral program areas. The selection and ranking of scholarly journals in each of the five marketing subareas is based on the average unweighted normalized ranking of input from marketing doctoral program directors/chairs, journal editors, the literature, and citation data. The ranking of scholarly journals by marketing subarea offer an objective ranking of journal quality for use by marketing departments, doctoral programs, doctoral candidates and scholars wishing to submit their manuscripts to the most influential journals in their marketing subarea.
\end{abstract}

Despite a proliferation of journals devoted to the marketing discipline, from 261 in 2006 up 98\% to 517 in 2011 (Cabell, 2011, 2006), marketing journal ranking studies consistently rank the top five scholarly journals in marketing as Journal of Marketing, Journal of Marketing Research, Journal of Consumer Research, Marketing Science and the Journal of the Academy of Marketing Science (Bauerly and Johnson, 2005; Yoo, 2009; Baumgartner and Pieters, 2003). Nonetheless, ranking journals representing scholarship in the field of marketing as a whole overlooks additional journal collections of top tier scholarly journals representing discrete and sizeable subareas. This study continues work on subareas of marketing (Baumgartner and Pieters, 2003; Chan et al 2011; Gorman et al, 2011; Kumar and Kwon, 2004; Hult et al, 2009) by (a) focusing on all major subareas of marketing and (b) using a multi-item measure approach to journal ranking.

To identify the most common marketing subareas, the study focused on sustained subareas offered by marketing doctoral programs in the US. Of the 108 schools was sourced from the AMA (2011), six schools were removed as they do not offer the doctoral program. The websites of the useable sample of 102 schools were examined to identify specializations offered in the marketing doctoral program. When this was not clear, the program director of the program was e-mailed and invited to list the institution's marketing doctoral program specializations.

Seeking input regarding the top tier scholarly journals in each of the five subareas of marketing followed a sequential solicitation of journal ranks from key informant groups. The first group was 62 marketing doctoral program directors (referred to as 'institutional'), followed with editors of the journals cited by the program directors. For both groups, the emailed request to participate required three weekly waves. The next data source was marketing subarea journal ranking studies in the literature, resulting in two subarea ranking studies for each subarea with the exception of logistics \& SCM that included three ranking studies. As there was only one journal ranking study for international marketing, the second study used ranked journals in international business. Finally, average citations per article per journal over the decade 2002 to 2011 were sourced using the Google Scholar software (Harzing, 2011). Each of the four sources ranks (institutional, editor, literature, citations) were ranked by normalizing the raw data. The overall ranking score for each journal was a normalized average of the four source ranks.

Even though each subarea's overall ranking is the unweighted mean of four independent data sourced rankings, none of the marketing subareas is significantly related to the citation ranking, a remarkable finding given the practice that citation data is an unequivocal measure of scholarly impact. This finding strengthens the value of this study because although each subarea includes a 'top five' marketing journal (with high citations/article), these journals are not necessarily ranked highest overall. For all subareas, there is a significant relationship between overall ranking and institutional ranking suggesting that doctoral program directors/chairs, presumably as a result of their professional experience, are able to combine attitudinal and citation data into their assessment of journal quality. The lack of significant differences in average citations/article between each subareas' collection of journals encourages confidence that each subareas' collection of journals possess an overall similar level of scholarly impact according to citations/article, and that no one subareas' collection of journals outperforms another.

References available upon request

Proceedings of AMS' World Marketing Congress Cultural Perspectives in Marketing (C 2012 